\title{
The Influence of Estrogen and Progesterone on Parasympathetic Vasodilatation in the Rat Submandibular Gland
}

\author{
Joshua Smith², Michael Lindsay ${ }^{2}$, Roshanak Rahimian ${ }^{3}$, and Leigh Anderson ${ }^{1}$ \\ 1 Department of Anatomical Sciences, University of the Pacific Arthur A. Dugoni School of Dentistry (San \\ Francisco, CA 94115) \\ 2Dental Program, University of the Pacific Arthur A. Dugoni School of Dentistry (San Francisco, CA 94115) \\ 3Department of Physiology and Pharmacology, T.J. Long School of Pharmacy and Health Sciences, \\ University of the Pacific (Stockton, CA 95211)
}

\section{SUMMARY}

Previous studies suggest that NO- and $\mathrm{PGI}_{2}$-independent pathways play a greater role in parasympathetic vasodilatation in the submandibular glands (SMG) of female than of male rats. Thus, the purpose of this study was to determine whether estrogen and progesterone influence the relative contributions of $\mathrm{NO}$ and $\mathrm{PGI}_{2}$ to parasympathetic vasodilatation in the SMG. Vascular responses to chorda-lingual nerve stimulation were examined in sham-operated (SHAM) and ovariectomized (OVX) female rats and in OVX rats treated with either 17 $\beta$-estradiol alone or a combination of $17 \beta$-estradiol and progesterone. Compared with SHAM animals, increases in vascular conductance in OVX rats were reduced at 1,2 and $5 \mathrm{~Hz}(\mathrm{p}<0.05)$. Blood flow responses in OVX $+17 \beta$-estradiol and OVX $+17 \beta$-estradiol + progesterone rats were indistinguishable from those observed in SHAM animals. Indomethacin had no effect on vasodilatation in SHAM and OVX + 17ß-estradiol rats, but increased vascular responses in OVX animals $(\mathrm{p}<0.02)$. The addition of L-NAME resulted in a significant reduction in vasodilatation at all frequencies. In OVX rats treated with both estrogen and progesterone treatment, indomethatin caused a reduction in vasodilatation and L-NAME further diminished the remaining responses. Under these conditions, vasodilatation was due largely, if not exclusively, to direct parasympathetic rather than antidromic sensory nerve activation. Finally, both neuronally-derived and endothelium-derived NO appeared to be responsible for the NO-dependent vasodilatation, but endothelium-derived $\mathrm{NO}$ became increasingly important as the frequency of stimulation increased. We conclude that estrogen and progesterone influence parasympathetic vasodilatation through combined effects on $\mathrm{NO}-, \mathrm{PGI}_{2}-$ and non-NO/PGI 2 -mediated pathways.

\section{Keywords}

Endothelium; Nitric Oxide; Prostacyclin; Cyclooxygenase

\section{INTRODUCTION}

Furchgott and Zawadski (1980) were the first to report that the vasodilatory actions of acetylcholine and other agonists, such as bradykinin, were dependent on the presence of an intact endothelium, and subsequently nitric oxide (NO) was identified as this endotheliumderived relaxing factor (Ignaro et al., 1987). However, other endothelium-derived vasodilators,

\footnotetext{
*All Correspondence and Proofs should be addressed to: Dr. Leigh C. Anderson Department Anatomical Sciences University of the Pacific Arthur A. Dugoni School of Dentistry 2155 Webster Street San Francisco, CA 94115 TEL: (415) 929-6413 FAX: (415) 749-3339 EMAIL: landerso@pacific.edu.
} 
including metabolites of arachidonic acid derived via the cyclooxygenase, epoxygenase and lipooxygenase pathways, as well as a variety of substances that share the common defining characteristic of activating $\mathrm{Ca}^{++}$-regulated potassium channel-dependent hyperpolarization of vascular smooth muscle (endothelium-derived hyperpolarizing factors or EDHF), have since been identified (Busse et al., 2002: Mombuli \& Vanhoutte, 1999; Félétou \& Vanhoutte, 2004). Moreover, the relative contribution of each of these factors to local control of vascular tone appears to be inversely related to vessel size.

Under resting conditions blood flow in the rat submandibular gland is largely under the control of sympathetic nerves, but vascular resistance is rapidly lowered by parasympathetic activity leading to an increase in glandular perfusion. The increase in blood flow during parasympathetic stimulation has been attributed to the release of endothelium-derived vasodilators (Edwards, 1998), and both NO-dependent and NO-independent mechanisms are involved (Anderson and Garrett, 1998). More recent studies (Anderson et al., 2006) have shown that in addition to $\mathrm{NO}$, both prostacyclin $\left(\mathrm{PGI}_{2}\right)$ and a $\mathrm{NO}-\mathrm{PGI}_{2}$-independent mechanism, which is usually attributed to EDHF, contributes to parasympathetic vasodilatation in the rat submandibular gland (Anderson et al., 2006). Furthermore, in the absence of NO synthesis this third pathway appears to compensate completely for the subsequent loss of $\mathrm{PGI}_{2}$-mediated vasodilatation. Furthermore, gender differences were observed when $\mathrm{PGI}_{2}$ pathway was inhibited before NO synthesis is blocked. Under those conditions, the putative EDHF-mediated vasodilatation was significantly reduced in males, whereas it appeared to compensate for the combined loss of both $\mathrm{NO}$ and $\mathrm{PGI}_{2}$ in females.

In the rat submandibular gland parasympathetic nerve stimulation is mediated by the co-release of acetylcholine and neuropeptides, such as substance $\mathrm{P}$ and vasoactive intestinal peptide (VIP) from nerve terminals, and as in other vascular beds the actions of parasympathetic nerve activity on blood flow have been thought to be largely, if not completely, endothelium-dependent (Edwards, 1998). However, Tobin et al. (1997) reported that the vasodilatory response to intravenously administered acetylcholine was not reduced following the administration of $\mathrm{N}^{\omega}$-nitro-L-arginine methyl ester (L-NAME), an inhibitor of nitric oxide synthase (NOS), whereas vasodilatory responses to VIP were. In addition to acetylcholine and neuropeptides, immunocytochemical evidence suggests that NO released from nerves may also play a role in glandular function. Neuronal NOS (nNOS) has been localized in parasympathetic nerves surrounding acinar cells, ducts and blood vessels in several species, including rat (Soinila et al., 1996; Alm et al. 1997; Takai et al., 1999), cat (Lohinai et al., 1995), ferret (Alm et al., 1997) and humans (Konttinen, 1997). Nevertheless, there is as yet no direct evidence demonstrating that neuronally-derived NO contributes to NO-dependent, parasympathetic vasodilatation in salivary glands.

Gender differences in the relative contributions of endothelium-derived vasodilators, on the other hand, have been studied extensively (see Thompson and Khalil, 2003; Orshal and Khalil, 2004), and there is general agreement that NO release is enhanced in the aorta and coronary arteries of females compared with those of males (Thompson and Khalil, 2003). In contrast, NO may be of greater functional importance in tail and mesenteric arteries in males than in females (McCulloch \& Randall, 1998; Pak et al., 2002). An increased contribution of EDHF to vascular reactivity in female arteries and arterioles has also been reported (White et al., 2000; Golding and Kepler, 2001; Wu et al., 2001; Pak et al., 2002; Wangensteen et al., 2004). Finally, in NO-deficient states flow-induced responses in arterioles are reported to be due entirely to EDHF in females, whereas $\mathrm{PGI}_{2}$ appears to be the major endothelium-derived vasodilator in males (Sun et al., 1999; Huang et al., 2001a; Wu et al., 2001).

Gender differences in vascular reactivity may be due, in part, to the influence of sex hormones on endothelial cell function. Estrogen, progesterone and testosterone all have cardiovascular 
effects, and estrogen in particular is thought to provide numerous cardiovascular benefits through both genomic and non-genomic effects on the synthesis and release of NO (Orshal \& Khalil, 2004). For example, estrogen upregulates eNOS gene expression (Rahimian et al., 2002,2004 ) and increases eNOS activity through increases in intracellular $\mathrm{Ca}^{+2}$ (Rahimian et al., 1998), phosphorylation of the enzyme (Haynes et al; 2000) and reduced superoxide $\left(\mathrm{O}_{2}{ }^{-}\right)$ production (Florian et al., 2004). In addition to its effects on NO, estrogen also influences arachidonic acid metabolism and the formation of $\mathrm{PGI}_{2}$ via cyclooxygenase activity, as well as the production of EDHF (Wu et al., 2001; Huang et al., 2001b).

Thus, we tested the hypothesis that the effects of estrogen alone or the combination of estrogen and progesterone influence in the vasodilatory responses to parasympathetic stimulation of the submandibular gland. Parasympathetically-evoked increases in submandibular vascular conductance (SVC) were measured in female rats after ovariectomy, and following the treatment of ovavriectomized animals with either $17 \beta$-estradiol alone or the combination of $17 \beta$-estradiol and progesterone. The findings presented in this paper demonstrate that estrogen deficiency (ovariectomy) alone can not account for the gender difference in vascular responses to parasympathetic stimulation. However, the data do support the hypothesis that estrogen deficiency results in a shift in the balance between vasodilatory and vasoconstrictor influences, which can be reversed by estrogen treatment. In addition, we present evidence that the combination of estrogen and progesterone significantly increases the relative contributions of $\mathrm{NO}$ and $\mathrm{PGI}_{2}$ to parasympathetic vasodilatation. Finally, we offer preliminary data suggesting that NO-dependent parasympathetic vasodilatation in the rat submandibular gland is due to the actions of both endothelium-derived and neuronal NO.

\section{METHODS}

\section{Animals}

A total of 36 female Sprague-Dawley rats (Simonsen Laboratories Inc., Gilroy, CA) were used during these studies. Animals were divided into four treatment groups: ovary-intact (SHAM, $\mathrm{n}=9$ ), ovariectomized (OVX, $\mathrm{n}=6)$, OVX $+17 \beta$-estradiol $(\mathrm{n}=6)$, and OVX $+17 \beta$-estradiol and progesterone $(n=6)$. All surgical procedures were carried out under sterile conditions.

For ovariectomies the rats were anesthetized ( $46 \mathrm{mg} \mathrm{kg}^{-1}$ ketamine and $4.6 \mathrm{mg} \mathrm{kg}^{-1}$ xylazine, Sigma Chemical Co., St. Louis, MO) and small incisions were made on each flank. The ovaries and their surrounding fat were externalized and after ligation of the ovarian arteries the ovaries were removed. The distal ends of each uterine horn were then returned to the peritoneal cavity and the incisions were closed with 4-0 nylon sutures. Each rat the received an intramuscular injection of $0.1 \mathrm{ml}$ Penicillin G procaine (300,000 units $\mathrm{ml}^{-1}$, Phoenix Pharmaceutical Inc., St. Joseph, MO) as a prophylactic measure. Three weeks after ovariectomy, animals in the hormone replacement groups were re-anesthetized and 21-day release pellets containing a total of $0.5 \mathrm{mg} 17 \beta$-estradiol or $15 \mathrm{mg}$ progesterone (Innovatiave Research of America, Sarasota, FL) were implanted subcutaneously, as described by Rahimian et al. (1997a).

All animals were maintained on a $12 \mathrm{~h}: 12 \mathrm{~h}$, light:dark cycle and allowed free access to food and water. Housing conditions and experimental protocols were approved by the Animal Use and Care Committee of the University of the Pacific.

\section{Parasympathetic Nerve Stimulation}

Three weeks after ovariectomy, or ovariectomy and an additional three weeks of hormone treatment, blood flow responses to parasympathetic stimulation were measured using laserDoppler Flowmetry. Anesthesia was induced with sodium pentobarbital $\left(35 \mathrm{mg} \mathrm{kg}^{-1}\right.$, i.p. $)$ followed by the chloralose $\left(80 \mathrm{mg} \mathrm{kg}^{-1}\right.$, i.v.). For parasympathetic nerve stimulation, the 
chorda-lingual nerve was exposed and carefully reflected onto the submandibular duct. Both the duct and the nerve were then placed on a bipolar electrode and parasympathetic impulses were delivered at consecutively higher frequencies of $1,2,5$ and $10 \mathrm{~Hz}(5-6 \mathrm{~V}, 2 \mathrm{~ms}$ duration). At the end of each experiment the rats were euthanized by the intracardiac administration of sodium pentobarbital $\left(50 \mathrm{mg} \mathrm{kg}^{-1}\right)$.

Systemic mean arterial blood pressure (MABP) was monitored continuously via a blood pressure transducer placed in the femoral artery. The trachea was cannulated to ensure a clear airway, but the animal was not artificially ventilated. Body temperature was maintained between $37^{\circ} \mathrm{C}$ and $38^{\circ} \mathrm{C}$ using a heated surgical table.

\section{Laser-Doppler Flowmetry}

The posterior, lateral quadrant of each right submandibular gland was exposed by creating a small window through the skin and overlying subcutaneous tissue. A laser-Doppler stainless steel probe (MP3a, Moor Instruments, London, UK) was placed at right angles to the gland without applying pressure to the tissue. Preliminary experiments demonstrated that placement of the probe over several different areas within the same quadrant resulted in comparable perfusion recordings. At the end of each stimulation period, blood flow was allowed to return to resting levels before the next stimulus was applied. After the administration of each inhibitor, a twenty minute waiting period was observed before the series of parasympathetic stimulations was repeated.

Laser-Doppler flowmetry measures blood flow in arbitrary perfusion units (laser-Doppler flux, LDF) and submandibular vascular conductance (SVC) was calculated (SVC=LDF / MABP). Parasympathetic vasodilatation was then expressed as the integral of the $\mathrm{SVC}_{\text {stimulated }}$ minus $\mathrm{SVC}_{\text {basal }}$. All data were captured, stored and analyzed using PowerLab $\odot$ acquisition software (ADInstruments, Colorado Springs, CO).

\section{Inhibition of Nitrix Oxide Synthases and Cyclooxygenase}

Cyclooxygenase activity was inhibited by the intraperitoneal administration of indomethacin $\left(5 \mathrm{mg} \mathrm{kg}^{-1}\right)$, and nitric oxide production was then blocked by the continuous intravenous

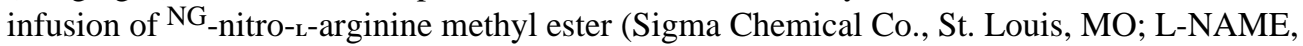
$5 \mathrm{mg} \mathrm{kg}^{-1}$ minute $\left.^{-1}\right)$. In a second set of control, non-ovariectomized animals $(\mathrm{n}=7)$ the role of nNOS in parasympathetic vasodilatation was determined by measuring changes in SVC following the intravenous administration of $\mathrm{N}^{\omega}$-propyl-L-arginine (Cayman Chemical Co., Ann Arbor, MI; N-PLA, bolus injection of $60 \mathrm{mg} \mathrm{kg}^{-1}$ and then continuous infusion at $1 \mathrm{mg} \mathrm{kg}^{-1}$ $\mathrm{min}^{-1}$ ) followed by the administration of L-NAME (as above). The dose of N-PLA was selected based on previous studies by Aras and Ektström (2008).

\section{Contribution of Parasympathetic vs Sensory Innervation}

In a third and final set of animals $(\mathrm{n}=4)$, blood flow was measured before and after the administration of hexamethonium chloride (Sigma Chemical Co., St. Louis, MO; 15-20 mg $\mathrm{kg}^{-1}$ i.p.) to block ganglionic transmission.

\section{Statistical Analysis}

Data were generally expressed as mean \pm standard deviation and analyzed for statistical significance using a one-way repeated analysis of variance with the $\alpha$ level set at 0.05 . Differences between treatment means were then tested using Dunnett's test for multiple comparisons. Differences between treatment groups were analyzed using Student's t test. 


\section{RESULTS}

\section{Body and Uterine Weights}

Final body and uterine weights are given in Table 1. Ovariectomy resulted in a significant increase in mean body weight compared with ovary-intact female rats, but uterine weights were dramatically reduced $(\mathrm{p}<0.001)$. Chronic treatment with $17 \beta$-estradiol alone or in combination with progesterone reversed the effects of ovariectomy on both body and uterine weights.

\section{MABP and Basal Vascular Conductance}

Over all treatment groups MABP was $120 \pm 19 \mathrm{~mm} \mathrm{Hg}$ and, and although there was a tendency for MABP to be increased in both OVX and OVX + 17 $\beta$-estradiol + progesterone-treated animals, the differences amongst treatment groups were not significant: SHAM, $113 \pm 17 \mathrm{~mm}$ Hg; OVX, $129 \pm 21 \mathrm{~mm} \mathrm{Hg}$; OVX + 17 $\beta$-estradiol, $113 \pm 12$ mm Hg; OVX + 17ß-estradiol +progesterone, $123 \pm 22 \mathrm{~mm} \mathrm{Hg}$. When indomethacin was administered ( $5 \mathrm{mg} \mathrm{kg}^{-1}$ i.p. $)$ a small, but significant, decrease in blood pressure was observed $(-11 \pm 4 \mathrm{mmHg}, \mathrm{p}<0.05)$. The addition of L-NAME $\left(3 \mathrm{mg} \mathrm{kg}^{-1}\right.$ minute $^{-1}$, i.v.) resulted in a dramatic increase in MABP (35 $\pm 5 \mathrm{~mm} \mathrm{Hg}, \mathrm{p}<0.05)$.

For any given animal, basal perfusion (measured as LDF) remained stable over the course of an experiment. Repeated parasympathetic stimulations had no effect on basal perfusion expressed in flux units, and after each stimulation period perfusion values returned to the levels recorded prior to stimulation. However, when glandular perfusion was calculated as SVC, basal perfusion was found to be significantly reduced after the administration of L-NAME (155 \pm 7 compared with $191 \pm 8, \mathrm{p}<0.001)$. In contrast, indomethacin had no apparent effect on basal conductance (201 \pm 7 compared with $191 \pm 8)$.

\section{Effects of Ovariectomy, $17 \beta$-estradiol alone or $17 \beta$-estradiol and Progesterone combined on Parasympathetic Vasodilatation}

In the absence of inhibitors, parasympathetic stimulation elicited frequency-dependent increases in glandular perfusion (see open bars, Figure 1). When expressed as a percent increase in SVC (mean \pm S.D.), parasympathetic vasodilatation in SHAM rats was $35 \pm 20 \%$ at $1 \mathrm{~Hz}$, $84 \pm 35 \%$ at $2 \mathrm{~Hz}, 206 \pm 53 \%$ at $5 \mathrm{~Hz}$ and $277 \pm 41 \%$ at $10 \mathrm{~Hz}$. Similar frequency-dependent responses were observed in each of the other three groups (Figure 1). However, the increases in SVC were significantly lower in OVX rats at 1,2 and $5 \mathrm{~Hz}$ than in SHAM rats. Treatment of OVX rats with either $17 \beta$-estradiol or a combination of $17 \beta$-estradiol and progesterone restored the observed vasodilatory responses to those of SHAM animals.

\section{The Relative Contributions of NO- and $\mathrm{PGI}_{2}$-dependent and $\mathrm{NO} / \mathrm{PGI}_{2}$-independent Pathways to Parasympathetic Vasodilatation}

The effects of indomethacin and L-NAME on vascular responses are shown in Figure 2. In SHAM animals, the administration of indomethacin to block cyclooxygenase activity had no apparent effect on the blood flow response, whereas the addition of L-NAME to block NO synthesis reduced parasympathetic vasodilatory response at all frequencies $(\mathrm{p}<0.05)$. As noted above, ovariectomy led to a decrease in blood flow responses to parasympathetic stimulation, and in contrast to the observations in SHAM rats, glandular perfusion was significantly increased following the administration of indomethacin $(\mathrm{p}<0.05)$ at all frequencies greater than $1 \mathrm{~Hz}$. As in SHAM rats, the addition of L-NAME resulted in a significant reduction in blood flow response to stimulation at all frequencies $(\mathrm{p}<0.05)$. Treatment of OVX rats with $17 \beta$ estradiol restored the pattern of glandular responses to that seen in the SHAM group. Finally, when OVX animals were treated with a combination of $17 \beta$-estradiol and progesterone, the effects of indomethacin and L-NAME were markedly different from those observed in the 
other three groups. After the administration of indomethacin, blood flow responses were significantly diminished at all frequencies $(\mathrm{p}<0.05)$ except $10 \mathrm{~Hz}$, and the addition of L-NAME resulted in a further reduction in vasodilatation at all frequencies $(\mathrm{p}<0.05)$.

\section{The Effects of Ganglionic Blockade on Parasympathetic Vasodilatation}

In a separate group of SHAM rats $(n=4)$ blood flow responses to parasympathetic stimulation were tested before and after the administration of hexamethonium to block ganglionic transmission. Hexamethomium had no apparent effect on MABP, but the vasodilatory responses (increase in SVC) were reduced by $90-95 \%$ at each frequency compared with the responses before ganglionic blockade.

\section{The Effects of N-propyl-L-arginine (N-PLA) vs L-LNAME}

The effects of N-PLA (a specific inhibitor of nNOS) followed by the addition of L-NAME on parasympathetic vasodilatation were tested in a final groups of SHAM rats $(\mathrm{n}=5)$ and the data are shown in Figure 3. Mean arterial blood pressure was unaffected by N-PLA, but the blood flow responses to parasympathetic stimulation were significantly reduced by the administration of N-PLA at $1 \mathrm{~m} 2$ and $5 \mathrm{~Hz}(\mathrm{p}<0.05)$. The addition of L-NAME led to a significant increase in MABP, similar to that seen in previous experiments. At $1 \mathrm{~Hz}, \mathrm{~L}-\mathrm{NAME}$ had no further effect on SVC. However, at 2,5 and $10 \mathrm{~Hz}$ the addition of L-NAME resulted in a significant reduction in $\mathrm{SVC}(\mathrm{p}<0.05)$.

\section{DISCUSSION}

In response to neurotransmitters, hormones, hypoxia and shear stress endothelial cells synthesize and release a variety of vasoactive substances, including the potent vasodilators $\mathrm{NO}, \mathrm{PGI}_{2}$ and an as yet incompletely characterized hyperpolarizing factor (EDHF). Depending on the vascular bed under study, EDHF has been variously identified as $\mathrm{H}_{2} \mathrm{O}_{2}$, potassium ions, intercellular communication via myoendothelial gap junctions or metabolites of arachidonic acid derived via the epoxygenase pathway (Félétou \& Vanhoutte, 2004). It should also be noted that the relative contribution of each of these vasodilators depends on the species, the vascular bed under study (e.g., mesenteric vs cerebral vessels) and vessel size. In general, NO is the predominant endothelium-derived vasodilator in large conductance vessels, whereas EDHF becomes increasingly important as vessel size decreases (Mombuli \& Vanhoutte, 1999;; Félétou \& Vanhoutte, 2004).

Salivary glands are supplied with an extremely dense microvascular network and, because of their accessibility they have proven to be an excellent model for the study of vascular biology. Both sympathetic and parasympathetic nerves regulate of secretory activity in salivary glands, and a coincident influence of autonomic nerves on glandular blood flow was originally demonstrated in the 19th century by Heidenhain (1857) and Bernard (1858). Sympathetic activity stimulates protein secretion and, depending on the experimental protocol employed, leads to either an intense vasoconstriction (continuous impulse generation) or a net vasodilatation (burst stimulation) (Anderson et al., 1988). In contrast, parasympathetic nerve stimulation evokes a copious secretion of fluid, which is accompanied by a conspicuous increase in glandular perfusion (Anderson and Garrett, 1998).

In a previous communication, we confirmed that both NO-dependent and NO-independent mechanisms contribute to parasympathetic vasodilatation in the rat submandibular gland (Anderson and Garrett, 1998). More recently the influence of gender on the relative contributions of each pathway to parasympathetic vasodilatation was examined (Anderson et al., 2006) and $\mathrm{NO}$, as well as $\mathrm{PGI}_{2}$ and a $\mathrm{NO} / \mathrm{PGI}_{2}$-independent vasodilatory mechanism (assumed to be an EDHF), were all determined to play a role in the vascular responses to 
parasympathetic stimulation. Although $\mathrm{NO}$ and the presumptive EDHF were the predominant vasodilators in the submandibular gland, the contribution of the NO/PGI pathway was greater in the glands of female rats than in those of males. In contrast, $\mathrm{PGI}_{2}$ appeared to be more important in males that in females (Anderson et al., 2006).

The present study extends our previous observations on the effects of gender, and its purpose was to specifically test the hypothesis that either estrogen alone or the combination of estrogen and progesterone are responsible for the sexual dimorphism in parasympathetic vasodilatation seen in the rat submandibular gland. When compared with our previously reported observations, it became apparent that estrogen deficiency alone does not account for the differences in submandibular vascular responses between male and female animals. Nevertheless, it was also clear that both estrogen and progesterone influence parasympathetic vasodilatation in the SMG.

Estrogen has both genomic and non-genomic effects on NO synthesis, bioavailability and vascular smooth muscle responsiveness (Orshal and Kahlil, 2003). For example, estrogen upregulates NO-mediated vascular reactivity in rat and rabbit aorta (Calderone, et al., 2001; Hayashi et al., 1992; Lam et al., 2006; Rahimian et al., 1997a,b, 2002), rabbit basilar arteries (Egami et al., 2005), cerebral arteries (Skarsgard et al., 1997; Geary et al., 2000), mesenteric arteries (Case and Davison, 1999) and muscle arterioles (Huang et al., 1997,1998). In contrast, several studies suggest that in mesenteric arteries NO-mediated relaxation is relatively unaffected or even decreased by estrogen, whereas as the contribution of EDHF is increased (Nawate et al., 2005; Sakuma et al., 2002, Liu et al., 2001, 2002; Scotland et al., 2005).

In the present study, parasympathetic stimulation led to frequency-dependent increases in vascular conductance in all groups. Although acetylcholine is the main neurotransmitter released from parasympathetic nerves in the submandibular gland, an atropine-resistant parasympathetic vasodilatation has been observed in several species including the cat (Lundberg et al. 1981; Edwards and Garrett, 1993), ferret (Tobin et al. 1991, 1997), pig (Modin et al. 1994), rat (Darke and Smaje, 1972; Thulin, 1976; Templeton and Thulin, 1978; Anderson and Garrett, 1998). This atropine-resistant vasodilatation is due to the co-release of neuropeptides, such as vasoactive intestinal peptide (VIP) and substance P (Ekström, 1999), and in the rat submandibular gland both substances appear to play a role in this phenomenon (Anderson and Garrett, 1998). At very low frequencies, the release of acetylcholine predominates, but with increasing stimulation frequency the contribution of neuropeptides increases dramatically, and approximately $50-60 \%$ of the vasodilatory response to parasympathetic stimulation is atropine-resistant (Anderson et al., 2006).

Sensory nerves also contain substance $\mathrm{P}$, and because the chorda-lingual nerve, rather than the chorda alone, was placed on the electrode, antidromic sensory nerve activation could have accounted for the some of the vasodilatory effect observed in this study. However, the administration of hexamethonium (a ganglionic blocker) resulted in a 90-95\% decrease in vasodilatation. The remaining vasodilatory response could still have been due to a small amount of antidromic sensory nerve activation. However, the stimulating electrode was placed very near the hilus of the gland where the ganglion cells are located (Ng et al., 1995). Thus, we can not rule out the possibility that the preparation was partially postganglionic, as opposed to completely preganglionic, in nature.

Submandibular vascular responses to parasympathetic nerve stimulation $(1,2$ and $5 \mathrm{~Hz})$ were reduced three weeks after ovariectomy, and treatment of OVX rats with 17ß-estradiol for three weeks reversed the effects of ovariectomy. Although serum estrogen levels were not measured directly, the marked decrease in uterine weight following ovariectomy suggests that there was a marked decrease in circulating estrogen levels. Similarly, the apparent effect of estrogen 
treatment on uterine weight in OVX rats suggests that the implantation of slow-release pellets containing $17 \beta$-estradiol restored serum estrogen concentrations to approximately physiological levels.

It should also be noted that some of the variability in the sham-operated group might be due to changes in circulating levels of estrogen in a normally cycling animal. However, the present study was designed to investigate the effects of the loss and replacement of female sex hormones rather than of the estrous cycle per se. We used female Sprague-Dawley rats (14-18 weeks of age), which is approximately 8-12 weeks after adult estrogen levels are attained in the rat. According to our previous report on the plasma $17 \beta$-estradiol levels in 16 week old adult female rats (Rahimian et al., 1997a), and a report by Moien-Afshari et al. (2003) who investigated the plasma concentrations of $17 \beta$-estradiol in rats aged 3 months to 21 months, the $17 \beta$-estradiol levels are stable over time and remain elevated when compared with male rats. In neither study were plasma $17 \beta$-estradiol levels reported at fixed phases of the estrus cycle.

The administration of L-NAME consistently resulted in a significant decrease in blood flow responses to parasympathetic stimulation. However, the magnitude of the effect of L-NAME did not appear to be altered by ovariectomy or estrogen-treatment of OVX animals. In contrast, indomethacin had no apparent effect on vasodilatation in SHAM and OVX + 17 $\beta$-estradiol rats, but interestingly led to an increase in blood flow responses following ovariectomy. Together, these data support the hypothesis by Ospina et al. (2003) that estrogen deficiency affects the relative balance between vasoconstrictor and vasodilator influences mediated via a cyclooxygenase-dependent pathway.

In endothelial cells arachidonic acid liberated form membrane phospholipids is metabolized through the activity of cyclooxygenase-1 (COX1) and cyclooxygenase-2 (COX2) to form prostaglandin $\mathrm{H}_{2}\left(\mathrm{PGH}_{2}\right)$, which can then be metabolized further by $\mathrm{PGI}_{2}$ synthase to form $\mathrm{PGI}_{2}$ (a vasodilator). Although $\mathrm{PGH}_{2}$ can also be metabolized to form thromboxane $\left(\mathrm{TxA}_{2}\right.$, a vasoconstrictor), very little $\mathrm{TxA}_{2}$ is synthesized within endothelial cells and it is $\mathrm{PGH}_{2}$ itself that binds to $\mathrm{TxA}_{2} / \mathrm{PGH}_{2}$ receptors to cause vasoconstriction. For a more complete review of the role cyclooxygenase in vascular function see Davidge (2001).

The effects of estrogen deficiency and $17 \beta$-estradiol on the pathways leading to $\mathrm{PGH}_{2}$ and $\mathrm{PGI}_{2}$ synthesis have been examined in a number of vascular beds, and many of these studies have been summarized recently by Villar et al. (2006). Of particular interest to our observations, Ospina et al. (2003) demonstrated similar physiological effects of ovariectomy and estrogen replacement on vascular tone in rat cerebral arteries, which were correlated with decreases and increases in the levels of COX1 and $\mathrm{PGI}_{2}$ synthase protein, respectively (Ospina et al., 2002). In addition, Davidge and Zhang (1998) reported a reduction in vascular responsiveness in mesenteric arteries to methacholine that was reversed in the presence of either cyclooxygenase inhibitors or $\mathrm{TxA}_{2} / \mathrm{PGH}_{2}$ receptor blockers. Estrogen has also been shown to upregulate COX1 expression in fetal pulmonary artery endothelial cells (Jun et al., 1998) and Gibson et al. (2005) demonstrated that the effects of estrogen were mediated by estrogen receptors. Based on their observation, Ospina et al. (2003) thus hypothesized that estrogen shifts the balance away from the predominance of the vasoconstrictor $\left(\mathrm{PGH}_{2}\right)$ and towards the vasodilatory influence of $\mathrm{PGI}_{2}$. It should be noted, however, that in mesenteric arteries Davidge and Zhang (1998) also found that there was an increase in the sensitivity of vascular smooth muscle to cyclooxygenase-dependent vasoconstrictors.

As noted earlier, non-NO/PGI 2 pathways appear to play a greater role in the vasodilatory responses to parasympathetic stimulation in the submandibular glands of female than of male rats (Anderson et al., 2006). Although not definitively identified, it was assumed that the 
remaining vasodilatory response was due to EDHF. Gender differences in EDHF-mediated vascular responses have also been observed in skeletal muscle (Wu et al., 2001), mesenteric arteries (McCulloch and Randall, 1998; White et al., 2000; Sakuma et al., 2002) and rat tail arteries (Pak et al., 2002). However, in contrast to the reported effects of ovariectomy and estrogen replacement on EDHF-mediated responses in mesenteric arteries (Liu et al., 2001, 2002; Sakuma et al., 2002; Nawate et al., 2005), estrogen deficiency and replacement appear to have minimal effects on a putative EDHF-mediated parasympathetic vasodilatation in the rat submandibular gland. Chataigneau and Schini-Kerth (2005) recently pointed to the diversity of the reported effects of ovariectomy on both NO and EDHF-mediated responses, and they specifically noted examples of contradictory evidence with respect to EDHF (Chataigneau et al., 2004, Golding and Kepler, 2001; Xu et al., 2002). Thus, the basis for the observed gender difference in NO/PGI2-indpendent responses in the rat submandibular gland remains to be determined.

An intriguing finding in the present study was that vascular effects of indomethacin and LNAME in OVX rats treated with a combination of $17 \beta$-estradiol and progesterone were markedly different from those of the other groups. The vasodilatory responses to parasympathetic stimulation were similar to those seen in the other three groups, but after the administration of indomethacin there was a significant reduction in parasympathetic vasodilatation. The addition of L-NAME then further lowered the response to parasympathetic stimulation, particularly at 5 and $10 \mathrm{~Hz}$. These data suggest that combined treatment with $17 \beta$-estradiol and progesterone significantly reduces the contribution of $\mathrm{NO} / \mathrm{PGI}_{2}$-independent mechanisms to vascular responses in the submandibular gland, while substantially increasing the contributions of $\mathrm{NO}$ and $\mathrm{PGI}_{2}$.

There are very few studies that document effects of progesterone on endothelial production of $\mathrm{NO}$ or $\mathrm{PGI}_{2}$, and no published reports on progesterone and EDHF activity were found in the literature. Therefore, the basis for the observed decrease in the $\mathrm{NO} / \mathrm{PGI}_{2}$-independent pathway remains a matter of speculation. One possibility is that progesterone has a direct, negative influence on the synthesis or activity of one or more of the putative EDHFs. Alternatively, the effects of combined estrogen and progesterone may occur indirectly, as a consequence of interactions that occur amongst the different pathways. In contrast to the well-documented effects of estrogen on vascular tone, those of progesterone are less clear, but progesterone may enhances both NO production and activity (Selles et al., 2002; Chan et al, 2001), as well as $\mathrm{PGI}_{2}$ synthesis in human umbilical vein (Hermenegildo et al., 2005) and ovine uterine (Rupnow et al., 2001) endothelial cells. Progesterone also appears to exert a direct effect on $\mathrm{PGI}_{2}$ synthesis in the aorta (Selles et al., 2002). This becomes particularly important when it is considered that there are interactions amongst the different pathways leading to the production of endothelium-derived vasodilators. Although the direction and magnitude of some of these interactions remain controversial, particularly those observed between eNOS and cyclooxygenase, $\mathrm{NO}$ has been postulated to have a negative regulatory effect on EDHF synthesis (Bauersachs et al. 1996; Nishikawa et al., 2000). Thus, an increase in NO-mediated vascular responses, and possibly those mediated by $\mathrm{PGI}_{2}$ as well, may be responsible for a compensatory reduction in $\mathrm{NO} / \mathrm{PGI}_{2}$-independent vasodilatation in the submandibular gland.

Lastly, while the regulation of eNOS activity has generally been the focus of studies examining the effects of sex hormones on vascular function, other sources of NO may play an important physiological role within both vascular and non-vascular tissues. In salivary glands, nNOS has been immunolocalized in parasympathetic nerves (Soinila et al., 1996, 2006; Alm et al., 1997; Takai et al., 1999), and NO may also be produced by the glandular parenchyma (see Looms et al., 2002). There has been speculation that NO derived from parasympathetic nerves may play a role in the regulation of glandular blood flow (Schacter et al., 1992; Soinila et al., 1996), but there is little published evidence to support the hypothesis. However, the release of 
NO from parasympathetic nerves has been implicated in the choroidal blood flow responses to sensory stimulation of the eye (Shimura, et al. 2002).

Although not conclusive, our observation that N-PLA, a highly specific inhibitor of nNOS (Zhang et al., 1997), completely inhibits parasympathetic vasodilatation at very low stimulation frequencies $(1 \mathrm{~Hz})$ and partially inhibits the vasodilatory response at higher frequencies $(2 \mathrm{~Hz}$ and $5 \mathrm{~Hz}$ ) suggests that neuronally-derived $\mathrm{NO}$ does play a role in the submandibular. The apparently complete inhibition of vasodilatation at $1 \mathrm{~Hz}$ may be related to the findings of Tobin et al. (1997), if it is assumed that acetylcholine release predominates over neuropeptide release. In contrast, at higher frequencies the vascular effects of neuropeptides, which are mediated via both NO-dependent and NO-independent mechanisms (Anderson et al., 2006), may have overwhelmed any contribution of neuronally-derived NO. Finally, based on the further inhibition of parasympathetic vasodilatation at $2 \mathrm{~Hz}, 5 \mathrm{~Hz}$ and $10 \mathrm{~Hz}$ followed the administration of LNAME endothelium-derived NO appears to play role in parasympathetic vasodilatation. Thus, it would be interesting to determine whether sex hormones affect the expression of either eNOS in the gland or nNOS in the submandibular ganglion.

In conclusion, we have demonstrated that the loss of estrogen results in a diminished vasodilatory response to parasympathetic stimulation, and that estrogen reverses the effects of ovariectomy. Our observations failed to support our hypothesis that the effects of estrogen are primarily responsible for the gender differences reported previously. It would be interesting, therefore, to examine the role of testosterone in males. Nonetheless, the data do support the hypothesis that estrogen regulates the balance between endothelium-dependent vasoconstrictor and vasodilator influences, possibly via estrogen-specific actions on both the NO- and $\mathrm{PGI}_{2}$ dependent pathways. In addition, in the submandibular gland the combination of estrogen and progesterone enhances $\mathrm{NO}$ - and $\mathrm{PGI}_{2}$-mediated vascular responses, but it diminishes those attributable to a presumptive EDHF. Finally, in addition to endothelium-derived NO, NO released from parasympathetic nerve terminals appears to play a role in the regulation of blood flow in the rat submandibular gland.

\section{ACKNOWLEDGEMENT}

This study was supported by a grant from the NIDCR (R15 DE016587).

\section{REFERENCES}

Alm P, Ekström J, Larsson B, Tobin G, Andersson KE. Nitric oxide synthase immunoreactive nerves in rat and ferret salivary glands, and effects of denervation. Histochem J 1997;29:669-676. [PubMed: 9413740]

Anderson LC, Garrett JR, Proctor GB. Advantages of burst stimulation for inducing sympathetic salivary secretion in rats. Q. J. Exp. Physiol 1988;73:1025-1028. [PubMed: 3237982]

Anderson LC, Garrett JR. Neural regulation of blood flow in the rat submandibular gland. Eur J Morphol 1998;36:213-218. [PubMed: 9825925]

Anderson LC, Martin DJ, Phillips DL, Killpack KJ, Bone SE, Rahimian R. The influence of gender on parasympathetic vasodilatation in the submandibular gland of the rat. Exp Physiol 2006;91:435-444. [PubMed: 16364982]

Aras HC, Ekstrom J. Pentagastrin-induced nitric oxide-dependent protein secretion from the parotid gland of the anesthetized rat. Exp Physiol 2008;91:977-982. [PubMed: 16873455]

Bauersachs J, Popp R, Hecker M, Sauer E, Fleming I, Busse R. Nitric oxide attenuates the release of endothelium-derived hyperpolarizing factor. Circulation 1996;94:3341-3347. [PubMed: 8989149]

Bernard C. De l'influence de deux orders de nerfs qui determinent les variations de coleur du sang vaisseaux dans les organes glandulaires. C R Acad Sci 1858;47:245-253.

Busse R, Edwards G, Feltou M, Fleming I, Vanhoutte PM, Weston AH. EDHF: bringing the concepts together. Trends Pharmacol Sci 2002;23:374-380. [PubMed: 12377579] 
Calderone V, Baragatti B, Breschi MC, Nieri P, Martinotti E. Hormonal influences on the release of endothelial nitric oxide: gender-related dimorphic sensitivity of the rat aorta to noradrenaline. J Pharm Pharmacol 2002;54:523-528. [PubMed: 11999130]

Case J, Davison CA. Estrogen alters relative contributions of nitric oxide and cyclooxygenase products to endothelium-dependent vasodilation. J Pharmacol Exp Ther 1999;291:524-530. [PubMed: 10525067]

Chan HY, Yao X, Tsang SY, Chan FL, Lau CW, Huang Y. Differential role of endothelium/nitric oxide in 17ß-estradiol- and progesterone-induced relaxation in rat arteries. Life Sci 2001;69:1609-1617. [PubMed: 11589501]

Chataigneau T, Zerr M, Chataigneau M, Hudlett F, Hirn C, Pernot F, Schini-Kert VB. Chronic treatment with progesterone but not medroxyprogesterone acetate restores the endothelial control of vascular tone in the mesenteric artery of ovariectomized rats. Menopause 2004;11:255-263. [PubMed: 15167304]

Chataigneau T, Schini-Kertfh VB. Vascular effects of ovariectomy and chronic oestrogen treatment in rats: controversy or experimental protocol diversity? Br J Pharmacol 2005;144:161-163. [PubMed: 15655505]

Darke AC, Smaje LH. Dependence of functional vasodilation in the cat submaxillary gland upon stimulation frequency. J Physiol 1972;226:191-203. [PubMed: 5083168]

Davidge ST. Prostaglandin H synthase and vascular function. Circ Res 2001;89:650-660. [PubMed: 11597987]

Davidge ST, Zhang Y. Estrogen replacement suppresses a prostaglandin H synthase-dependent vasoconstrictor in rat mesenteric arteries. Circ Res 1998;83:388-395. [PubMed: 9721695]

Edwards, AV. Autonomic control of blood flow. In: Garrett, JR.; Ekström, J.; Anderson, LC., editors. Glandular Mechanisms of Salivary Secretion. Karger; Basel: 1998. p. 101-117.

Edwards AV, Garrett JR. Nitric oxide-related vasodilator responses to parasympathetic stimulation of the submandibular gland of the cat. J Physiol 1993;464:379-392. [PubMed: 8229808]

Egami R, Tanaka Y, Nozaki M, Koera K, Okuma A, Nakano H. Chronic treatment with 17beta-estradiol increases susceptibility of smooth muscle cells to nitric oxide. Eur J Pharmacol 2005;520:142-149. [PubMed: 16135361]

Ekström, J. Role of nonadrenergic, noncholinergic autonomic transmitters in salivary glandular activities in vivo. In: Garrett, JR.; Ekström, J.; Anderson, LC., editors. Neural Mechanisms of Salivary Secretion. Karger; Basel: 1999. p. 94-130.

Félétou M, Vanhoutte PM. EDHF: new therapeutic targets? Pharmacol Res 2004;49:565-580. [PubMed: 15026034]

Fleming I. Cytochrome P450 epoxygenase as EDHF synthase(s). Pharmacol Res 2004;49:525-533. [PubMed: 15026030]

Florian M, Freiman A, Magder S. Treatment with 17-beta-estradiol reduces superoxide production in aorta of ovariectomized rats. Steroids 2004;69:779-87. [PubMed: 15582532]

Furchgott RF, Zawadzki JV. The obligatory role of endothelial cells in the relaxation of arterial smooth muscle by acetylcholine. Nature (London) 1980;288:373-376. [PubMed: 6253831]

Geary GG, Krause DN, Duckles SP. Estrogen reduces mouse cerebral artery tone through endothelial NOS- and cyclooxygenase-dependent mechanisms. Am J Physiol 2000;279:H511-H519.

Gibson LL, Halmer L, Osborne-Lawrence S, German Z, Wu KK, Chambliss KL, Shaul PW. Molecular basis of estrogen-induced cyclooxygenase type I upregulation in endothelial cells. Circ Res 2005;96:518-525. [PubMed: 15705965]

Golding EM, Kepler TE. Role of estrogen in modulating EDHF-mediated dilations in the female rat middle cerebral artery. Am. J. Physiol 2001;280:H2417-H2423.

Haynes MP, Sinha D, Russell KS, Collinge M, Fulton D, Morales-Ruiz M, Sessa WC, Bender JR. Membrane estrogen receptor engagement activates endothelial nitric oxide synthase via the PI3kinase-Akt pathway in human endothelial cells. Circ. Res 2000;87:677-682. [PubMed: 11029403]

Heidenhain R. Uber dir Wirkung eineger Gifte auf die Nerven die glandula sumaxillaris. Pflug Arch 1872;5:309-318. 
Hermenegildo C, Oviedo PJ, Garcia-Martinez MC, Garcia-Perez MA, Tarin JJ, Cano A. Progestogens stimulate prostacyclins production by human endothelial cells. Hum Reprod 2005;20:1554-1561. [PubMed: 15734756]

Hayashi T, Fukuto JM, Ignarro LJ, Chaudhuri G. Basal release of nitric oxide from aortic rings is greater in female rabbits than in male rabbits: implications for atherosclerosis. Proc Natl Acad Sci 1992;89:11259-11263. [PubMed: 1454805]

Huang A, Sun D, Carroll MA, Jiang H, Smith CJ, Connetta JA, Kalck JR, Shelsey EG, Koller A, Kaley G. EDHF mediates flow-induced dilation in skeletal muscle arterioles of female eNOS-KO mice. Am J Physiol 2001a;280:H2462-H2469.

Huang A, Wu Y, Sun D, Koller A, Kaley G. Gender difference in myogenic tone in rat arterioles is due to estrogen-induced, enhanced release of NO. Am J Physiol 1997;272:H1804-H1809. [PubMed: 9139966]

Huang A, Wu Y, Sun D, Koller A, Kaley G. Gender difference in flow-induced dilation and regulation of shear stress: role of estrogen and nitric oxide. Am J Physiol 1998;275:R1571-R1577. [PubMed: 9791075]

Huang A, Wu Y, Sun D, Koller A, Kaley G. Effect of estrogen on flow-induced dilation in NO deficiency: role of prostaglandins and EDHF. J Appl Physiol 2001b;91:2561-2566. [PubMed: 11717219]

Ignarro LJ, Buga GM, Wood KS, Byms RE, Chauduri G. Endothelium-derived relaxing factor produced and released from artery and vein is nitric oxide. Proc Natl Acad Sci 1987;84:9265-9269. [PubMed: 2827174]

Jun SS, Chen Z, Pace MC, Shaul PW. Estrogen upregulates cyclooxygenase-1 gene sxpression in ovine fetal pulmonary artery endothelium. J Clin Invest 1998;102:176-183. [PubMed: 9649571]

Konttinen YT, Platts LAM, Tuominen S, Eklund KK, Santavirta N, Törnwall J, Sorsa T, Hukkanen M, Polak JM. Role of nitric oxide in Sjögren's syndrome. Arthrit Rheumat 1997;40:875-883.

Lam KK, Lee HY, Hsiao G, Chen SY, Yen MH. Estrogen therapy replenishes vascular tetrahydrobiopterin and reduces oxidative stress in ovariectomized rats. Menopause 2006;13:294302. [PubMed: 16645543]

Liu MY, Hattori Y, Sato A, Ichikawa R, Zhang XH, Sakuma I. Ovariectomy attenuates hyperpolarization and relaxation mediated by endothelium-derived hyperpolarizing facto in femalke mesenteric artery: a concomitant decrease in connexin-43 expression. J Cardiovasc Pharmacol 2002;40:38-48.

Liu MY, Hattori Y, Fukao M, Sato A, Sakuma I, Kanno M. Alterations in EDHF-mediated hyperpolarization and relaxation in mesenteric arteries of female rats in long-term deficiency of oestrogen and during oestrus cycle. Br J Pharmacol 2002;132:1035-1046. [PubMed: 11226134]

Lohinai, Zs.; Székely, AD.; Soós, L.; Fehér, E. Distribution of nitric oxide synthase containing elements in the feline submandibular gland. Neurosci Lett 1995;192:9-12. [PubMed: 7545801]

Looms D, Trisaris K, Pedersen AM, Nauntofte B, Dissing S. Nitric oxide signaling in salivary glands. J Oral Pathol Med 2002;31:569-584. [PubMed: 12406302]

Lundberg JM, Änngård A, Farenjkrug J. Complementary role of vasoactive intestinal polypeptide (VIP) and acetylcholine for cat submandibular gland blood flow and secretion. II. Effects of cholinergic antagonists and VIP antiserum. Acta Physiol Scand 1981;113:329-336. [PubMed: 7345899]

McCulloch AI, Randall MD. Sex differences in the relative contributions of nitric oxide to agoniststimulated endothelium-dependent relaxations in rat isolated mesenteric arterial bed. Br J Pharmacol 1998;123:1700-1706. [PubMed: 9605578]

Moien-Afshari F, Kenyon E, Choy JC, Battistini B, McManus B, Laher I. Long-term effects of ovariectomy and estrogen replacement treatment on endothelial function in mature rats. Maturitas 2003;45:213-23. [PubMed: 12818467]

Modin A, Weitzberg E, Lundberg JM. Nitric oxide regulates peptide release from parasympathetic nerves and vascular reactivity to vasoactive intestinal peptide in vivo. Eur J Pharmacol 1994;261:185-197. [PubMed: 8001643]

Mombouli J-V, Vahoutte PM. Endothelial dysfunction: From physiology to therapy. J Mol Cell Cardiol 1999;31:61-74. [PubMed: 10072716]

Nawate S, Fukao M, Sakuma I, Soma T, Nagai K, Takikawa O, Miwa S, Kitabatake A. Reciprocal changes in endothelium-derived hyperpolarizing facto- and nitric oxide-system in the mesenteric artery of adult female rats following ovariectomy. Br J Pharmacol 2005;144:178-189. [PubMed: 15655506] 
Nishikawa Y, Stepp DW, Chilian WM. Nitric oxide exerts feedback inhibition on EDHF-induced coronary arteriolar dilation. Am J Physiol 2000;280:H2456-2461.

$\mathrm{Ng}$ YK, Wong WC, Ling EA. A study of the structure and functions of the submandibular ganglion. Ann Acad Med Singapore 1995;24:793-801. [PubMed: 8838983]

Orshal JM, Khalil RA. Gender, sex hormones, and vascular tone. Am J Physiol 2004;286:R233-R249.

Ospina JA, Duckles SP, Krause DN. 17 $\beta$-Estradiol decreases vascular tone in cerebral arteries by shifting COX-dependent vasoconstriction to vasodilation. Am J Physiol 2003;285:H241-H250.

Ospina JA, Krause DN, Duckles SP. 17ß-estradiol increases rat cerebrovascular prostacyclin synthesis by elevating cyclooxygenase-1 and prostacyclin synthase. Stroke 2002;33:660-605.

Pak KJ, Geary GG, Duckles SP, Krause DN. Male-female differences in the relative contribution of endothelial vasodilators released by rat tail artery. Life Sci 2002;71:1633-1642. [PubMed: 12137910]

Rahimian R, Laher I, Dube G, van Breemen C. Estrogen and selective estrogen receptor modulator, LY117018 enhance release of nitric oxide in rat aorta. J. Pharmacol. Exp. Ther 1997a;283:116-122. [PubMed: 9336315]

Rahimian R, van Breeman C, Karkan D, Dube G, Laher I. Estrogen augments cyclopiazonic acidmediated, endothelium-dependent vasodilation. Eur J Pharmacol 1997b;327:143-149. [PubMed: 9200552]

Rahimian R, Wang X, van Breemen C. Gender difference in the basal intracellular $\mathrm{Ca}^{2+}$ concentration $\left(\left[\mathrm{Ca}^{2+}\right]_{\mathrm{i}}\right)$ in rat valvular endothelial cells. Biochem. Biophys. Res. Commu 1998;248:916-919.

Rahimian R, Dubé G, Toma W, Dos Santos N, McManus B, van Breemen C. Raloxifene enhances nitric oxide release in rat aorta via increasing eNOS mRNA expression. Eur. J. Pharmacol 2002;434:141149. [PubMed: 11779577]

Rahimian R, Chan L, Goel A, Poburko D, van Breemen C. Estrogen modulation of endothelium-derived relaxing factor by human endothelial cells. Biochem. Biophys. Res. Commu 2004;322:373-379.

Rupnow HL, Phernetton TM, Shaw CE, Modrick ML, Bird IM, Magness RR. Endothelial vasodilator production by uterine and system arteries. VII. Estrogen and progesterone effects on eNOS. Am J Physiol 2001;280:H1699-H1705.

Sakuma I, Liu M-Y, Sato A, Hayashi T, Iguchi A, Kitabatake A, Hattori Y. Endothelium-dependent hyperpolarization and relaxation in mesenteric arteries of middle-aged rats: influence of oestrogen. Br J Pharmacol 2002;135:48-54. [PubMed: 11786479]

Schacter M, Matthews B, Bhoola KD. Evidence that nitric oxide or a related substance is a neurovasodilator in the submandibular gland of the cat. Agents Actions 1992;38(Suppl):366-370.

Scotland RS, Madhami M, Chauhan S, Moncada S, Andresen J, Nilsson H, Hobbs AJ, Ahluwalia A. Investigation of vascular responses in endothelial nitric oxide synthase/cyclooxygenase-1 doubleknockout mice. Key role for endothelium-derived hyperpolarizing factor in regulation of blood pressure in vivo. Circulation 2005;111:796-803. [PubMed: 15699263]

Selles J, Polini N, Alvarez C, Massheimer V. Nongenomic action of progesterone in rat aorta: role of nitric oxid and prostaglandins. Cell Signal 2002;14:431-436. [PubMed: 11882387]

Shimura M, Uchida S, Suzuki A, Nakajima K, Aikawa Y. Reflex choroidal blood flow responses of the eyeball following somatic sensory stimulation in rats. Auton Neurosci 2002;97:35-41. [PubMed: 12036184]

Skarsgard P, van Breeman C, Laher I. Estrogen regulates myogenic tone in pressurized cerebral arteries by enhanced basal release of nitric oxide. Am J Physiol 1997;273:H2248-H2256. [PubMed: 9374760]

Soinila J, Nuorva K, Soinila S. Nitric oxide synthase in human salivary glands. Histochem Cell Biol 2006;125:717-723. [PubMed: 16341869]

Soinila S, Vanhatalo S, Lumme A, Back N, Soinila J. Nitric oxide synthase in the autonomic and sensory ganglia innervating the submandibular salivary gland. Microsc res Tech 1996;35:32-43. [PubMed: 8873057]

Sun D, Huang A, Smith CJ, Stackpole CJ, Connetta JA, Shelsey EG, Koller A, Kaley G. Enhanced release of prostaglandins contributes to flow-induced arteriolar dilation in eNOS knockout mice. Circ Res 1999;85:288-293. [PubMed: 10436172] 
Takai N, Uchihashi K, Higuchi K, Yoshida Y, Yamaguchi M. Localization of neuronal constitutive nitric oxide synthase and secretory regulation by nitric oxide in rat submandibular and sublingual glands. Archs Oral Biol 1999;44:745-750.

Templeton D, Thulin A. Secretory, motor and vascular effects in the sublingual gland of the rat caused by autonomic nerve stimulation. Q J Exp Physiol 1978;63:59-66.

Thompson J, Khalil RA. Gender differences in the regulation of vascular tone. Clin Exp Pharmacol Physiol 2003;30:1-15. [PubMed: 12542447]

Thulin A. Blood flow changes in the submaxillary gland of the rat on parasympathetic and sympathetic nerve stimulation. Acta Physiol Scand 1976;97:104-109. [PubMed: 1274631]

Tobin G, Edwards AV, Bloom SR, Ekström J. Nitric oxide in the control of submandibular gland function in the anaesthetized ferret. Exp Physiol 1997;82:825-836. [PubMed: 9331552]

Tobin G, Ekström J, Bloom SR, Edwards AV. Atropine-resistant submandibular responses to stimulation of the parasympathetic innervation in the anaesthetized ferret. J Physiol 1991;437:327-339. [PubMed: 1890638]

Villar IC, Francis S, Webb A, Hobbs AJ, Ahluwalia A. Novel aspects of endothelium-dependent regulation of vascular tone. Kidney Int 2006;70:840-853. [PubMed: 16837917]

Wangensteen R, Moreno JM, Sainz J, Rodriguea-Gomez I, Chamorro V, de Dios Luna J, Osuna A, Vargas F. Gender differences in the role of endotheliaum-derived relaxing factors modulating renal vascular reactivity. Eur J Pharmacol 2004;486:281-288. [PubMed: 14985050]

White RM, Rivera CO, Davison CA. Nitric oxide-dependent and -independent mechanisms account for gender differences in vasodilatation to acetylcholine. J Pharmacol Exp Ther 2000;292:375-380. [PubMed: 10604973]

Wu Y, Huang A, Dong S, Falck JR, Koller A, Kaley G. Gender-specific compensation for the lack of NO in the mediation of flow-induced arteriolar dilation. Am J Physiol 2001;280:H2456-2461.

Xu HL, Santizo RA, Baughman VL, Pelligrino DA. ADP-induced pial arteriolar dilation in ovariectomized rats involes gap-junctional communication. Am J Physiol 2002;283:H1082-1091.

Zhang HQ, Fast W, Marletta MA, Martasek P, Silvermann RB. Potent and selective inhibition of neuronal nitric oxide synthase by N $\omega$-propyl-1-arginine. J Med Chem 1997;40:3869-3870. [PubMed:

9397167] 


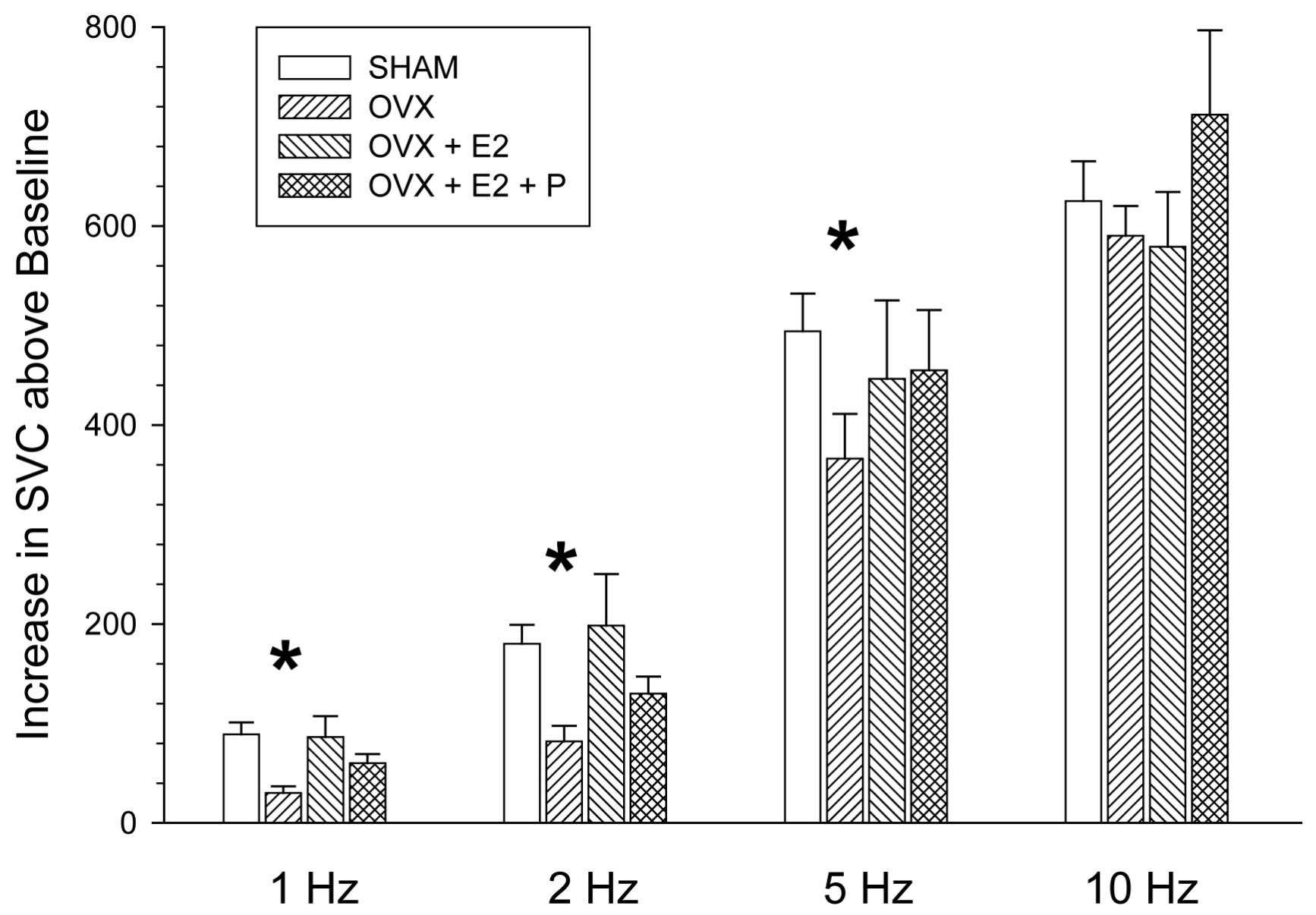

Figure 1. Parasympathetic vasodilatation in the submandibular gland of rats and following ovariectomy and treatment with either either $17 \beta$-estradiol alone or a combination of $17 \beta$-estradiol and progesterone

Each point represents the increase in $\mathrm{CVC}$ above basal conductance (mean \pm standard error of the mean): SHAM (n=9), OVX (n=6), OVX + 17 $\beta$-estradiol $(n=6)$, OVX + 17 $\beta$-estradiol + progesterone $(n=6)$. ${ }^{*} \mathrm{p}<0.05 \mathrm{OVX}$ vs all other treatment groups. 

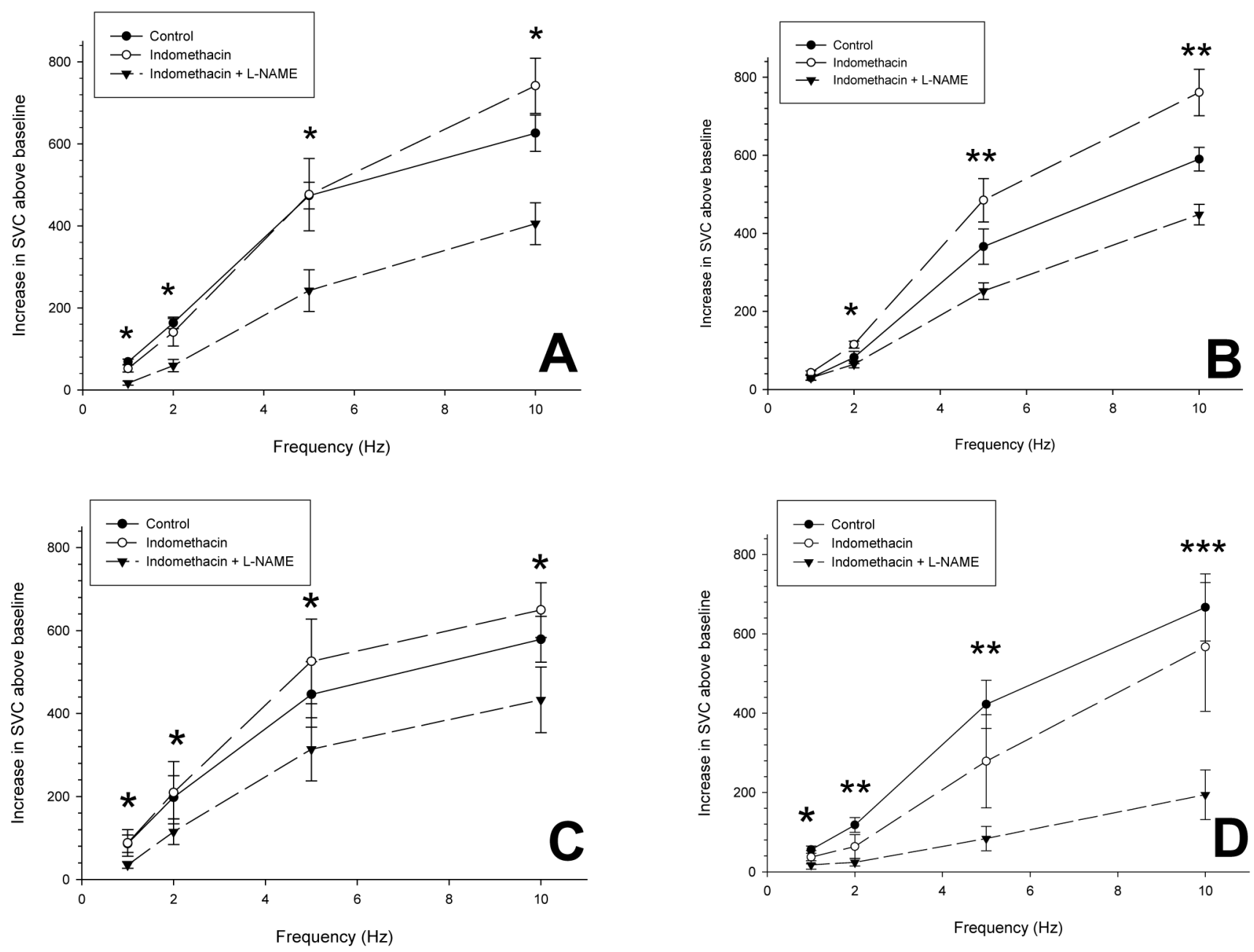

Figure 2. Effects of Inhibiting $\mathrm{PGI}_{2}$ and NO Synthesis on Parasympathetic Vasodilatation in the Rat Submandibular Gland

Perfusion was measured in the presence of indomethacin $\left(5 \mathrm{mg} \mathrm{kg}^{-1}\right.$, i.p.) followed by continuously infused L-NAME (5 mg $\mathrm{min}^{-1} \mathrm{~kg}^{-1}$, i.v.). Each point represents the increase in CVC above basal conductance (mean \pm standard error of the mean): Panel A, SHAM (n=9); Panel B, OVX (n=6); Panel C, OVX + 17 $\beta$-estradiol $(n=6)$; Panel D, OVX + 17 $\beta$-estradiol + progesterone $(n=6)$. Repeated measures ANOVA: Panel A, ${ }^{*} \mathrm{p}<0.05$ Indomethacin + L-NAME vs control and Indomethacin alone; Panel B, * $\mathrm{p}<0.05$ Indomethacin alone vs Control and Indomethacin + L-NAME, $* * \mathrm{p}<0.05$ all pairwise comparisons significantly different; Panel $\mathrm{C}, * \mathrm{p}<0.05$ Indomethacin + L-NAME vs Control and Indomethacin alone; Panel D, ${ }^{*} \mathrm{p}<0.05$ Indomethacin alone and Indomethacin + L-NAME vs Control, $* * \mathrm{p}<0.05$ all pairwise comparisons, $* * * \mathrm{p}<0.05$ Indomethacin + L-NAME vs Control and Indomethacin alone. 


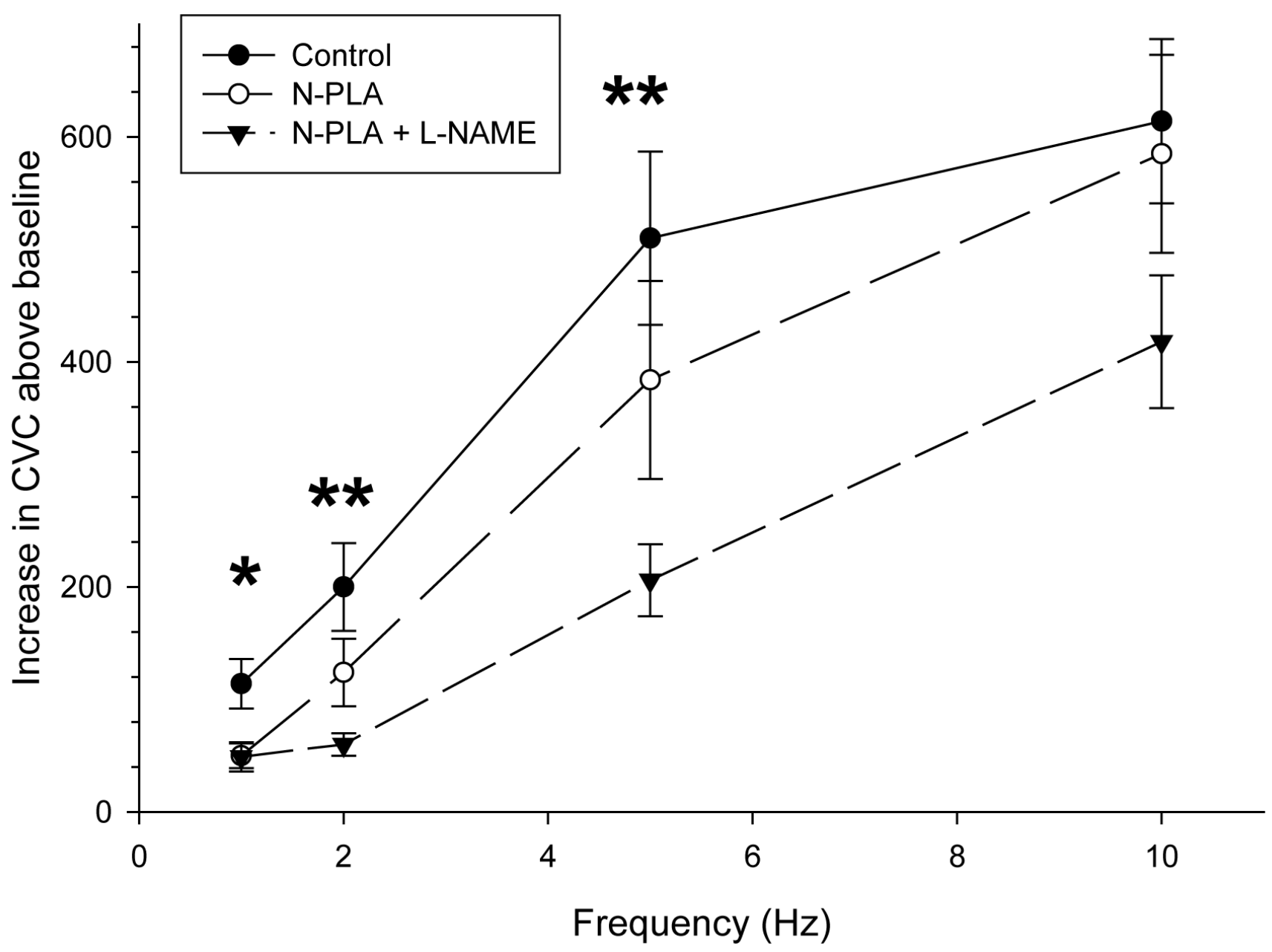

Figure 3. Effects of N-Propyl-L-Arginine (N-PLA) alone or incombination with L-NAME on Parasympathetic Vasodilatation in the Rat Submandibular Gland

Perfusion was measured in SHAM rats $(n=5)$ in before and after the administration of N-PLA (60 $\mathrm{mg} \mathrm{kg}^{-1}$, i.v.) alone or N-propyl-L arginine followed by continuously infused L-NAME $\left(5 \mathrm{mg} \mathrm{min}{ }^{-1} \mathrm{~kg}^{-1}\right.$, i.v.). Each point represents the increase in CVC above basal conductance (mean \pm standard error of the mean) Repeated measures ANOVA: * ${ }^{*}<0.05$ N-PLA alone and $\mathrm{N}-\mathrm{PLA}+\mathrm{L}-\mathrm{NAME}$ vs control; $* * \mathrm{p}<0.05$ all pairwise comparisons significantly diffferent; $* * * \mathrm{p}<0.05 \mathrm{~N}-\mathrm{PLA}+\mathrm{L}-\mathrm{NAME}$ vs Control and N-PLA alone. 
Table 1

Body and Uterine Weight

\begin{tabular}{|c|c|c|c|c|}
\hline & $\begin{array}{c}\text { Initial } \\
\text { Weight }(\mathbf{g})\end{array}$ & $\begin{array}{c}\text { Final } \\
\text { Weight }(\mathbf{g})\end{array}$ & $\begin{array}{c}\text { Uterus } \\
(\mathbf{m g})\end{array}$ & $\begin{array}{c}\text { Uterus/Body } \\
(\mathbf{m g} / \mathbf{g})\end{array}$ \\
\hline SHAM & $243 \pm 10^{*}$ & $260 \pm 9$ & $531 \pm 88$ & $2.05 \pm 0.38$ \\
\hline VX & $251 \pm 4$ & $298 \pm 15^{* *}$ & $178 \pm 27^{* *}$ & $0.59 \pm 0.08^{* *}$ \\
\hline OVX +E2 & $247 \pm 9$ & $249 \pm 10$ & $648 \pm 131^{* *}$ & $2.58 \pm 0.51^{* *}$ \\
\hline OVX+ E2+PG & $244 \pm 12$ & $259 \pm 9$ & $721 \pm 137^{* *}$ & $2.78 \pm 0.50^{* *}$ \\
\hline
\end{tabular}

Mean \pm S.E.M.

**

$\mathrm{p}<0.001$, Treatment groups vs SHAM 